\title{
Dietary Inflammatory Index and Risk of Multiple Sclerosis in a Case-Control Study from Iran
}

\author{
Nitin Shivappa ${ }^{\text {a-c }}$ James R. Hebert ${ }^{\text {a-c }}$ Maryam Behrooz $^{\text {d }}$ Bahram Rashidkhani $^{d}$ \\ ${ }^{a}$ Department of Epidemiology and Biostatistics, Arnold School of Public Health, ${ }^{b}$ Cancer Prevention and Control \\ Program, University of South Carolina, and ${ }^{\mathrm{C} C o n n e c t i n g ~ H e a l t h ~ I n n o v a t i o n s ~ L L C, ~ C o l u m b i a, ~ S . C ., ~ U S A ; ~}{ }^{\mathrm{d}}$ Department of \\ Community Nutrition, Faculty of Nutrition Sciences and Food Technology, National Nutrition and Food Technology \\ Research Institute (WHO Collaborating Center), Shahid Beheshti University of Medical Sciences, Tehran, Iran
}

\section{Key Words}

Diet $\cdot$ Inflammation $\cdot$ Multiple sclerosis

\begin{abstract}
Background: Diet and inflammation have been suggested to be important risk factors for multiple sclerosis (MS). Objectives: In this study, we examined the ability of the dietary inflammatory index (DII) to predict MS in a case-control study conducted in Iran. Methods: This study included $68 \mathrm{MS}$ cases and 140 controls hospitalized for acute non-neoplastic diseases. The DII was computed based on dietary intake assessed by a previously validated food frequency questionnaire. Logistic regression models were used to estimate ORs adjusted for age, energy, sex, body mass index, season of birth, rubella history, history of routine exercise before MS, smoking and history of consumption of cow's milk in the first 2 years of life. Results: Subjects with higher DII scores (i.e., with a more pro-inflammatory diet) had a higher risk of MS, with the DII being used both as a continuous variable $\left(\mathrm{OR}_{\text {continuous }} 1.66 ; 95 \% \mathrm{Cl} 1.19-2.31 ; 1\right.$ unit increase corresponding to $\approx 15 \%$ of its range in the current study) and a categorical variable $\left(\mathrm{OR}_{\mathrm{DII}}(>1.43\right.$ vs. $\leq 1.43) 2.68 ; 95 \% \mathrm{Cl} 1.15-$ 6.26). Conclusions: These results indicate that a pro-inflammatory diet is associated with increased risk of MS.
\end{abstract}

(c) 2016 S. Karger AG, Basel (c) 2016 S. Karger AG, Basel

$0251-5350 / 16 / 0471-0026 \$ 39.50 / 0$

\section{Introduction}

Chronic inflammation - which is characterized by the continuous presence of inflammatory cytokines in circulation and in the tissues - is known to play a key role in the development of various diseases of the central nervous system (CNS) [1,2]. In particular, it has been shown that chronic inflammation is important in triggering the development of multiple sclerosis (MS), which is also the most common inflammatory demyelinating disease of the CNS [1]. MS is the most common cause of neurological disability in young adults, with a distinctly higher prevalence between the ages of 20 and 40 years and among women [3]. The neurodegenerative disease disables patients with a wide range of chronic symptoms including fatigue, tremors, spasticity, pain, numbness of limbs, bowel and bladder dysfunction and cognitive problems [3]. Recent studies have shown a growing prevalence of MS in tropical and sub-tropical regions such as Iran, indicating that the distribution of MS is not following the latitude gradient exactly [4]. In Iran, incidence of MS has been increasing dramatically over recent years; Isfahan and Tehran provinces were defined as high-risk areas for MS $[5,6]$. The etiology of MS is complex and multifactorial and involves genetics as well as environmental factors such as diet and other aspects of lifestyle [6]. Several stud-

\section{KARGER}

E-Mail karger@karger.com

www.karger.com/ned
Prof. Bahram Rashidkhani

Department of Community Nutrition, Faculty of Nutrition Sciences and Food Technology National Nutrition and Food Technology Research Institute (WHO Collaborating Center) Shahid Beheshti University of Medical Sciences, Tehran 198396-3113 (Iran)

E-Mail rashidkhani@yahoo.com 
ies have examined the association between dietary intake and food groups and MS [7-12].

Diet represents a complex set of exposures that often interact, and the cumulative effect modifies both inflammatory responses and health outcomes. A literature-derived, population-based dietary inflammatory index (DII) was developed to assess the inflammatory potential of an individual's diet $[13,14]$ and has been validated with various inflammatory markers, including $\mathrm{C}$-reactive protein $[14,15]$, interleukin-6 $[16,17]$ and homocysteine [17]. Among other outcomes, DII has been shown to be associated with asthma in Australia [16], colorectal, pancreatic and prostate cancers [17-21].

Our hypothesis is that a higher DII score (indicating a pro-inflammatory diet) is associated with increased risk of incident MS. In the current study, we thus examined this putative association using a case-control study conducted in Iran [22]. This provided original information on an Iranian population where dietary and lifestyle habits and awareness of diet-related health issues are different from those in North America and Europe.

\section{Methods}

This was a hospital-based case-control study, conducted from March 2011 through January 2012 in Tehran city, the capital of Iran. Seventy cases were selected by sequential sampling from patients referred by Tehran MS Society to Sinai Hospital Neurology Clinics. Patients with MS clinically defined according to the McDonald criteria [23], who were diagnosed less than a year before recruitment, were included in the study. Other inclusion criteria were age between 20 and 60 years and that patients did not introduce changes to their diets since diagnosis. We included only incident cases in the study in order to reduce the probability that subjects changed their diet substantially since diagnosis. A total of 142 controls were recruited from the same hospital. They were admitted to the hospitals for various medical issues (eye or nose disorders, skin diseases, fractures and sprains, for trauma and injuries, and for other illnesses, for example, removal of plates, pins, screws and wires). Exclusion criteria for controls were previous diagnosis of cancer, inflammatory diseases of the peripheral nervous system, gastrointestinal and liver diseases, endocrine and metabolic disorders, immune system disorders and following a special diet (e.g., weight-loss or vegetarian diet). Controls were matched to cases on age ( \pm 5 years) and sex. Data for 2 controls and 2 cases were excluded from the analysis because their log scales of total energy intake were $>|3| \mathrm{SD}$ from the mean. The final study sample included 68 cases and 140 controls, representing a response rate of $85 \%$ for each. Protocols and procedures of this study were approved by the Ethics Board of the National Nutrition and Food Technology Research Institute (No. 114), Iran, and all participants provided written consent, after being informed of the purpose of this research, indicating their willingness to participate.

DII and MS
Professionally trained dietitians interviewed all cases and controls using structured pretested questionnaires. They evaluated the sociodemographic characteristics (age, sex, education, monthly family income and place of residence), birth season and location of patient, parental age at birth, feeding of cow's milk in infancy, history of rubella and measles infection, family history of MS, vitamin D supplement intake before disease diagnosis and smoking history (status, duration and intensity). Weight measurement was performed with subjects standing on digital scales (Soehne, Berlin, Germany), minimally clothed and without shoes, and weight was recorded to the nearest $100 \mathrm{~g}$. Height was measured without shoes using a non-stretch meter tape fixed to a wall, and it was recorded to the nearest $0.5 \mathrm{~cm}$. Body mass index (BMI) was calculated by dividing the subjects' weight in kilograms by the square of height in meters. Participants' dietary intake during the past year was assessed using a valid and reliable semi-quantitative food frequency questionnaire (FFQ) [24], which was based on the Harvard (Willett's) FFQ [25] modified to demonstrate an accurate representation of the Iranian diet. This interviewer-administered FFQ consists of 125 food items with standard serving sizes, and participants were asked to specify their consumption frequency for each food item on a daily, weekly, monthly or yearly basis. Nutrient consumption was then calculated using the Nutrients Composition of Iranian Foods [24] supplemented with the USDA Food Composition Data. The consumption of alcohol was not asked to our participants due to their cultural beliefs and concomitant low levels of intake and, therefore, was not included in the analysis. FFQ-derived dietary data were used to calculate DII scores for all participants. The DII is based on literature published through 2010 linking diet to inflammation. Individuals' intakes of food parameters on which the DII is based are then compared to a world standard database. A complete description of the DII is available elsewhere [13]. A description of validation work, including DII derived from both dietary recalls and a structured questionnaire similar to an FFQ and related to interval values of hs-CRP, is also available [14]. Briefly, to calculate DII for the participants of this study, their dietary data were first linked to the regionally representative world database that provided a robust estimate of a mean and SD for each parameter [13]. These then become the multipliers to express an individual's exposure relative to the 'standard global mean' as a $\mathrm{z}$-score. This is achieved by subtracting the 'standard global mean' from the amount reported and dividing this value by the SD. To minimize the effect of 'right skewing' (a common occurrence with dietary data), this value is then converted to a centered percentile score. The centered percentile score for each food parameter for each individual was then multiplied by the respective food parameter effect score, which is derived from the literature review, in order to obtain a food parameter-specific DII score for an individual. All of the food parameter-specific DII scores are then summed to create the overall DII score for every participant in the study [13]. A total of 27 food parameters were available from the FFQ and therefore could be used to calculate DII (carbohydrate, protein, total fat, fiber, cholesterol, saturated fat, mono-unsaturated fat, poly unsaturated fat, omega-3, omega-6, niacin, thiamin, riboflavin, vitamin B12, vitamin B6, iron, magnesium, selenium, zinc, vitamin A, vitamin C, vitamin $\mathrm{D}$, vitamin $\mathrm{E}$, folic acid, beta carotene, onion and pepper).

\section{Statistical Analyses}

The DII was analyzed both as a continuous variable and as a dichotomous variable, categorized based on the median value of the DII (+1.43). DII (as dichotomous) was examined across the 
Table 1. Characteristics of patients in an Iranian MS case-control study $(\mathrm{n}=208)$

\begin{tabular}{|c|c|c|}
\hline Characteristics & $\begin{array}{l}\text { Cases } \\
(\mathrm{n}=68)\end{array}$ & $\begin{array}{l}\text { Controls } \\
(\mathrm{n}=140)\end{array}$ \\
\hline Age, years, mean $\pm S D$ & $30.4 \pm 9.0$ & $30.6 \pm 8.0$ \\
\hline \multicolumn{3}{|l|}{ Gender, n (\%) } \\
\hline Male & $11(16.2)$ & $26(18.6)$ \\
\hline Female & $57(83.8)$ & $114(81.4)$ \\
\hline $\mathrm{BMI}, \mathrm{kg} / \mathrm{m}^{2}$, mean $\pm \mathrm{SD}$ & $25.1 \pm 5$ & $24.2 \pm 4.4$ \\
\hline $\mathrm{DII}$, mean $\pm \mathrm{SD}$ & $1.8 \pm 1.3$ & $1.2 \pm 1.7$ \\
\hline \multicolumn{3}{|c|}{ Cow milk consumption (within } \\
\hline No & $66(97.1)$ & $122(87.1)$ \\
\hline Yes & $2(2.9)$ & $18(12.9)$ \\
\hline \multicolumn{3}{|l|}{ Smoking ${ }^{\mathrm{a}}, \mathrm{n}(\%)$} \\
\hline Yes & $4(5.8)$ & $10(7)$ \\
\hline No & $64(94.2)$ & $130(93)$ \\
\hline Current smoker & $7(14.9)$ & $15(15.6)$ \\
\hline \multicolumn{3}{|l|}{ Season of birth, n (\%) } \\
\hline Spring & $26(38.2)$ & $41(30.4)$ \\
\hline Summer & $11(16.2)$ & $50(37.0)$ \\
\hline Autumn & $17(25)$ & $18(13.3)$ \\
\hline Winter & $14(20.6)$ & $26(19.3)$ \\
\hline \multicolumn{3}{|l|}{ Place of birth, $\mathrm{n}(\%)$} \\
\hline Tehran & $36(52.9)$ & $69(49.3)$ \\
\hline Others & $32(47.1)$ & $71(50.7)$ \\
\hline
\end{tabular}

following characteristics: age, sex, season of birth, BMI, smoking, history of rubella, cow milk consumption (within 2 first years of life) and history of routine exercise using Student $t$ test or $\chi^{2}$ test for continuous and categorical variables, respectively. ORs and 95\% CIs were estimated using logistic regression models, adjusting only for age, and then fitting a model with additional adjustment for sex, BMI, season of birth, rubella history, history of routine exercise before MS, smoking and history of consumption of cow's milk in the first 2 years of life. Statistical tests were performed using SAS $^{\circledR} 9.3$ (SAS Institute Inc., Cary, N.C., USA); all p values were based on 2-sided tests.

\section{Results}

The DII score in this study ranged from -2.48 (most anti-inflammatory score) to +4.17 (most pro-inflammatory score). Table 1 shows the distribution of 68 cases of MS and 140 controls according to selected variables. By design, age and sex distributions were similar in cases and controls. Among cases, there were proportionally many more women than men ( 83.8 vs. $16.2 \%)$. Compared to controls, more cases were fed cow's milk in infancy. A
Table 2. Participant characteristics by level of DII among controls, Iranian MS case-control study $(\mathrm{n}=208)$

\begin{tabular}{|c|c|c|c|}
\hline Variables & $\mathrm{DII} \leq 1.43$ & $3 \mathrm{DII}>1.43$ & $\mathrm{p}$ value $\mathrm{a}, \mathrm{b}$ \\
\hline Age, years, mean \pm SD & $30.3 \pm 8.4$ & $31.0 \pm 7.7$ & 0.61 \\
\hline $\mathrm{BMI}, \mathrm{kg} / \mathrm{m}^{2}$, mean $\pm \mathrm{SD}$ & $24.3 \pm 4.6$ & $24.2 \pm 4.3$ & 0.96 \\
\hline \multicolumn{4}{|l|}{ Routine exercise before the } \\
\hline diagnosis of multiple sclerosis, $\%$ & & & 0.04 \\
\hline No & 47.2 & 64.7 & \\
\hline Yes & 52.8 & 35.3 & \\
\hline Sex, \% & & & 0.14 \\
\hline Males & 13.9 & 23.5 & \\
\hline Females & 86.1 & 76.5 & \\
\hline Smoking, \% & & & 0.16 \\
\hline Non-smoker & 95.8 & 89.7 & \\
\hline Current smoker & 4.2 & 10.3 & \\
\hline \multicolumn{4}{|l|}{ Cow milk consumption } \\
\hline (within 2 first years of life), \% & & & 0.38 \\
\hline No & 84.7 & 89.7 & \\
\hline Yes & 15.3 & 10.3 & \\
\hline Season of birth, $\%$ & & & 0.67 \\
\hline Spring & 30.4 & 30.3 & \\
\hline Summer & 37.7 & 36.4 & \\
\hline Autumn & 10.1 & 16.7 & \\
\hline Winter & 21.7 & 16.7 & \\
\hline History of rubella, \% & & & 0.89 \\
\hline No & 55.6 & 54.4 & \\
\hline Yes & 44.4 & 45.6 & \\
\hline
\end{tabular}

a Student $\mathrm{t}$ test was used for continuous variables. ${ }^{\mathrm{b}}$ Chi-square test was used for categorical variables. Significance was at $\mathrm{p}<0.05$.

higher percentage of cases (25\%) were born in autumn compared to controls (13\%). The mean DII value among cases was 1.87 (SE 0.16) and among controls it was 1.20 (SE 0.14), indicating a more pro-inflammatory diet for cases (table 1).

Control characteristics across categories of DII are provided in table 2 . There were some differences in sociodemographic factors and lifestyle habits across DII categories. In particular, participants in DII $>1.43$ category were more likely to be men and current smokers, less likely to have a history of cow milk consumption within the first 2 years of life and less likely to have a history of routine exercise before the diagnosis of MS. However, the results were not significant except for history of routine exercise before the diagnosis of MS ( $p$ value $=0.03$ ).

ORs and 95\% CIs for the risk of MS are shown in table 3. Results obtained from modeling DII scores as a continuous variable in relation to risk of MS showed a positive association after adjustment for age (OR 1.32; 95\% CI 1.09-1.61) and in the multivariate analyses (OR 1.66; 95\% CI 1.19-2.31). When analysis was carried out with DII expressed as a dichotomous variable and adjust- 
Table 3. ORs and 95\% CIs for the association between DII and MS, Iranian MS case-control study $(\mathrm{n}=208)$

\begin{tabular}{|c|c|c|c|c|c|}
\hline & \multicolumn{2}{|c|}{ DII, OR (95\% CI) } & \multirow[t]{2}{*}{$\mathrm{p}$ value } & \multirow{2}{*}{$\begin{array}{l}\text { DII (continuous) } \\
\text { OR }(95 \% \text { CI })\end{array}$} & \multirow[t]{2}{*}{$\mathrm{p}$ value } \\
\hline & $\mathrm{DII} \leq 1.43$ & $\mathrm{DII}>1.43$ & & & \\
\hline Age-adjusted & 1 (ref.) & $2.07(1.14-3.79)$ & 0.02 & $1.32(1.09-1.61)$ & 0.005 \\
\hline Multivariate-adjusted $^{\mathrm{b}}$ & 1 (ref.) & $2.68(1.15-6.26)$ & 0.02 & $1.66(1.19-2.31)$ & 0.003 \\
\hline
\end{tabular}

ing for age, subjects with DII score $>1.43$ were more than twice as likely to have MS compared to subjects with DII $\leq 1.43\left(\mathrm{OR}_{\mathrm{DII}}(>1.43 / \leq 1.43) 2.07 ; 95 \%\right.$ CI $\left.2.63-21.70\right)$. After multivariable adjustment, subjects with DII $>1.43$ were more than $2 \frac{1}{2}$ times as likely to have MS compared to subjects with $\mathrm{DII} \leq 1.43\left(\mathrm{OR}_{\mathrm{DII}}(>1.43 / \leq 1.43) 2.68 ; 95 \% \mathrm{CI}\right.$ 1.15-6.26).

\section{Discussion}

In this case-control study, we found that subjects with higher DII scores (i.e., those who had the most pro-inflammatory diets) were at increased risk of developing MS, a result supporting our hypothesis that consuming a more pro-inflammatory diet is associated with an increased risk of MS.

Consumption of food items such as vegetables and fruits have been shown to reduce inflammation [26], while others, such as red and processed meat, increase inflammation [27]. Indeed, in this case-control study, a healthy nutrient pattern characterized by high consumption of riboflavin, vitamin $\mathrm{D}$, zinc, linolenic acid, vitamin $\mathrm{C}, \mathrm{b}$-carotene and vitamin A showed protective effects on MS [22]. By contrast, in the same study, no significant association was observed with nutrient patterns rich in thiamin, selenium, niacin, magnesium, poly unsaturated fatty acid, mono-unsaturated fatty acid, vitamin $\mathrm{E}$ and saturated fat [22]. Vitamin D has consistently been shown to be protective against MS $[7,10]$. In a 2005 review paper reporting the findings on the association between various nutrients and MS, vitamin D and vitamin B12 were found to be protective against MS, whereas inconsistent results were reported for selenium, omega- 3 and omega- 6 fatty acids and several other antioxidant vitamins and compounds [7]. In another case-control study conducted in Iran looking at various dietary patterns and risk of MS, a traditional dietary pattern was inversely related to the risk of MS (OR 0.15; 95\% CI 0.03-0.18; p = 0.028) [12]. A similar inverse relationship was noted between MS risk and lacto-vegetarian and vegetarian patterns (OR 0.31; 95\% CI $0.12-0.82 ; \mathrm{p}=0.018$ and OR 0.42 ; $95 \%$ CI $0.19-0.90$; $\mathrm{p}=0.026$, respectively) [12]. In contrast, the prevalence of MS was higher in those who had a high animal fat dietary pattern [12]. Similarly, previous studies that have examined the effect of specific food items on MS; i.e., in a large cohort study conducted among women in the USA, no associations were observed for fruits, vegetables, coffee and alcohol $[8,11]$. A limitation of this approach is that these foods or nutrients are usually consumed in combination; thus, dietary correlations may attenuate or accentuate the real effects of each food or nutrient under study. In formulating the DII, a different approach was taken by focusing on the functional effects of foods and nutrients. As such, it relies on reviewing and scoring of the peer-reviewed literature on the subject of diet and inflammation. Moreover, it standardizes individuals' dietary intakes of pro- and anti-inflammatory food constituents to world referent values, which results in values that are not dependent on idiosyncrasies of the units of consumption (e.g., simply expressing exposure in micrograms instead of milligrams) and can be used for comparison across studies.

One of the possible mechanisms for the observed direct association of the DII with MS is through the effect of pro-inflammatory diet on the levels of various inflammatory cytokines, such as vascular cellular adhesion molecule (VCAM), and T and B lymphocytes, all of which appear to be important components in the development of MS. An early event in this process is the binding of the lymphocyte integrin $\alpha 4 \beta 1$ (VLA-4) to VCAM-1 on the brain vascular endothelium, which results in the transmigration of leucocytes (including $\mathrm{T}$ lymphocytes, but also monocytes and other immune cells) into the CNS. This 
forms a crucial step because, on entering CNS, these lymphocytes lead to the formation of new inflammatory demyelinating lesions [1].

\section{Strengths and Limitations}

There are several strong points that should be considered in evaluating our study. It is the first study in Iran to explore the association between the inflammatory properties of diet and MS. The total participation rate for the both case and control groups was above $85 \%$. Additionally, we were able to conduct the study in a province with a high point prevalence of MS. To minimize selection bias, individuals in the control group were selected only from patients with conditions not related to diet or other major risk factors of MS. Besides these notable strengths, there are certain weaknesses that need to be considered. First, errors in self-reported dietary intake may lead to distortion of results. We know that such estimates may be plagued by disease-independent response sets, such as social approval and social desirability [28-30]. These were neither measured in the study nor do we know how they would function in Iranian culture. Such measurement errors may result in residual confounding [31,32]. Second, as with other case-control studies, disease-specific recall bias and selection bias may exist. For example, in case-control studies, there is the possibility that cases may recall their diets differently after a disease diagnosis [33-35]. However, in order to reduce the possibility of recall bias, only newly incident cases were enrolled as participants in our study. There also is the possibility that individuals would change diet as a consequence of their disease. Our strategy of recruiting only newly incident MS patients was meant minimize this problem. However, we cannot eliminate it entirely. More- over, using hospital controls and administering validated FFQs by trained interviewers in a hospital setting might have further reduced recall bias and improved comparability of information across cases and controls. Another limitation is the non-availability of appropriate data on physical activity. Future work should capture duration, frequency and intensity of physical activity, which is known to play a major role in modulating inflammation [36].

In conclusion, results from our study showed that subjects who consumed a more pro-inflammatory diet were at increased odds of having MS compared to those who consumed a more anti-inflammatory diet. However, more studies are required to confirm this association.

\section{Acknowledgement}

We are grateful to all field investigators, staffs and participants of the present study. This study was supported by a grant from National Nutrition and Food Technology Research Institute, Shahid Beheshti University of Medical Sciences, Tehran, IRAN. Drs. Shivappa and Hébert were supported by grant number R44DK103377 from the United States National Institute of Diabetes and Digestive and Kidney Diseases.

\section{Disclosure Statement}

Dr. J.R. Hebert owns controlling interest in Connecting Health Innovations LLC (CHI), a company planning to license the right to his invention of the DII from the University of South Carolina in order to develop computer and smart phone applications for patient counseling and dietary intervention in clinical settings. Dr. N. Shivappa is an employee of CHI. The subject matter of this paper will have no direct bearing on the work of $\mathrm{CHI}$ nor has any $\mathrm{CHI}$-related activity exerted any influence on this project.

\section{References}

1 Ciccarelli O, Barkhof F, Bodini B, De Stefano N, Golay X, Nicolay K, et al: Pathogenesis of multiple sclerosis: insights from molecular and metabolic imaging. Lancet Neurol 2014; 13:807-822.

2 Soilu-Hanninen M, Koskinen JO, Laaksonen M, Hanninen A, Lilius EM, Waris M: High sensitivity measurement of CRP and disease progression in multiple sclerosis. Neurology 2005;65:153-155

3 Compston A, Coles A: Multiple sclerosis. Lancet 2008;372:1502-1517.

4 Alonso A, Hernan MA: Temporal trends in the incidence of multiple sclerosis: a systematic review. Neurology 2008;71:129-135.

5 Etemadifar M, Maghzi AH: Sharp increase in the incidence and prevalence of multiple scle- rosis in Isfahan, Iran. Mult Scler 2011;17: 1022-1027.

6 Elhami SR, Mohammad K, Sahraian MA, Eftekhar H: A 20-year incidence trend (19892008) and point prevalence (March 20, 2009) of multiple sclerosis in Tehran, Iran: a population-based study. Neuroepidemiology 2011; 36:141-147.

7 Schwarz S, Leweling H: Multiple sclerosis and nutrition. Mult Scler 2005;11:24-32.

8 Massa J, O'Reilly EJ, Munger KL, Ascherio A: Caffeine and alcohol intakes have no association with risk of multiple sclerosis. Mult Scler 2013;19:53-58.

9 Ebers GC, Sadovnick AD, Veith R: Vitamin D intake and incidence of multiple sclerosis. Neurology 2004;63:939; author reply 939.
10 Munger KL, Zhang SM, O’Reilly E, Hernan MA, Olek MJ, Willett WC, et al: Vitamin D intake and incidence of multiple sclerosis. Neurology 2004;62:60-65.

11 Zhang SM, Hernan MA, Olek MJ, Spiegelman D, Willett WC, Ascherio A: Intakes of carotenoids, vitamin $\mathrm{C}$, and vitamin $\mathrm{E}$ and $\mathrm{MS}$ risk among two large cohorts of women. Neurology 2001;57:75-80.

12 Jahromi SR, Toghae M, Jahromi MJ, Aloosh M: Dietary pattern and risk of multiple sclerosis. Iran J Neurol 2012;11:47-53.

13 Shivappa N, Steck SE, Hurley TG, Hussey JR, Hebert JR: Designing and developing a literature-derived, population-based dietary inflammatory index. Public Health Nutr 2014; 17:1689-1696. 
14 Shivappa N, Steck SE, Hurley TG, Hussey JR, Ma Y, Ockene IS, Tabung F, Hebert JR: A population-based dietary inflammatory index predicts levels of C-reactive protein in the seasonal variation of blood cholesterol study (SEASONS). Public Health Nutr 2014;17: 1825-1833.

15 Wirth MD, Burch J, Shivappa N, Violanti JM, Burchfiel CM, Fekedulegn D, et al: Association of a dietary inflammatory index with inflammatory indices and metabolic syndrome among police officers. J Occup Environ Med 2014;56:986-989.

16 Wood LG, Shivappa N, Berthon BS, Gibson PG, Hebert JR: Dietary inflammatory index is related to asthma risk, lung function and systemic inflammation in asthma. Clin Exp Allergy 2015;45:177-183.

17 Shivappa N, Bosetti C, Zucchetto A, Serraino D, La Vecchia C, Hebert JR: Dietary inflammatory index and risk of pancreatic cancer in an Italian case-control study. Br J Nutr 2015 113:292-298.

18 Shivappa N, Bosetti C, Zucchetto A, Montella M, Serraino D, La Vecchia C, Hebert JR: Association between dietary inflammatory index and prostate cancer among Italian men. Br J Nutr 2015;113:278-283.

19 Shivappa N, Prizment AE, Blair CK, Jacobs DR Jr, Steck SE, Hébert JR: Dietary inflammatory index and risk of colorectal cancer in the Iowa women's health study. Cancer Epidemiol Biomarkers Prev 2014;23:2383-2392.

20 Tabung FK, Steck SE, Ma Y, Liese AD, Zhang J, Caan B, et al: The association between dietary inflammatory index and risk of colorectal cancer among postmenopausal women: results from the women's health initiative. Cancer Causes Control 2015;26:399-408.
21 Zamora-Ros R, Shivappa N, Steck SE, Canzian F, LandiS, Alonso MH, Hébert JR, Moreno V: Dietary inflammatory index and inflammatory gene interactions in relation to colorectal cancer risk in the Bellvitge colorectal cancer case-control study. Genes Nutr 2015; 10:447.

22 Akhoondan M, Behrooz M, Naja F, Jessri M, Hoseini Z, Rashidkhani B: Nutrient patterns and risk of multiple sclerosis: a case-control study. J Neurol Res 2014;4:72-80.

23 McDonald WI, Compston A, Edan G, Goodkin D, Hartung HP, Lublin FD, et al: Recommended diagnostic criteria for multiple sclerosis: guidelines from the International Panel on the diagnosis of multiple sclerosis. Ann Neurol 2001;50:121-127.

24 Mirmiran P, Esfahani FH, Mehrabi Y, Hedayati M, Azizi F: Reliability and relative validity of an FFQ for nutrients in the Tehran lipid and glucose study. Public Health Nutr 2010;13:654-662.

25 Willett WC, Hu FB: The food frequency questionnaire. Cancer Epidemiol Biomarkers Prev 2007;16:182-183.

26 Defago MD, Elorriaga N, Irazola VE, Rubinstein AL: Influence of food patterns on endothelial biomarkers: a systematic review. J Clin Hypertens (Greenwich) 2014;16:907-913.

27 Lopez-Garcia E, Schulze MB, Fung TT, Meigs JB, Rifai N, Manson JE, et al: Major dietary patterns are related to plasma concentrations of markers of inflammation and endothelial dysfunction. Am J Clin Nutr 2004;80:1029-1035.

28 Hebert Jr, Clemow L, Pbert L, Ockene IS Ockene JK: Social desirability bias in dietary self-report may compromise the validity of dietary intake measures. Int J Epidemiol 1995; 24:389-398.
29 Hebert JR, Ma Y, Clemow L, Ockene IS, Saperia G, Stanek EJ 3rd, et al: Gender differences in social desirability and social approval bias in dietary self-report. Am J Epidemiol 1997; 146:1046-1055.

30 Hebert JR, Ebbeling CB, Matthews CE, Hurley TG, Ma Y, Druker S, et al: Systematic errors in middle-aged women's estimates of energy intake: comparing three self-report measures to total energy expenditure from doubly labeled water. Ann Epidemiol 2002;12:577586

31 Fewell Z, Davey Smith G, Sterne JA: The impact of residual and unmeasured confounding in epidemiologic studies: a simulation study. Am J Epidemiol 2007;166:646-655.

32 Heitmann BL: Social desirability bias in dietary self-report may compromise the validity of dietary intake measures. Implications for diet disease relationships. Int J Epidemiol 1996;25:222-225.

33 Lindsted KD, Kuzma JW: Long-term (24year) recall reliability in cancer cases and controls using a 21-item food frequency questionnaire. Nutr Cancer 1989;12:135-149.

34 Kuzma JW, Lindsted KD: Determinants of long-term (24-year) diet recall ability using a 21-item food frequency questionnaire. Nutr Cancer 1989;12:151-160.

35 Holmberg L, Ohlander EM, Byers T, Zack M, Wolk A, Bruce Å, et al: A search for recall bias in a case-control study of diet and breast cancer. Int J Epidemiol 1996;25:235-244.

36 Huang CJ, Zourdos MC, Jo E, Ormsbee MJ: Influence of physical activity and nutrition on obesity-related immune function. Scientific WorldJournal 2013;2013:752071. 